\title{
CCK-A and CCK-B Receptors Enhance Olfactory Recognition via Distinct Neuronal Pathways
}

\author{
Martine Lemaire, ${ }^{1}$ Pascal Barnéoud, G. Andrees Böhme, Odile Piot, \\ Forrest Haun, ${ }^{2}$ Bernard P. Roques, ${ }^{3}$ and Jean-Charles Blanchard
}

Rhône-Poulenc Rorer S.A.

Neuroscience Research Program

Centre de Recherches de Vitry-Alfortville

94403 Vitry-sur-Seine cedex, France

${ }^{2}$ Department of Anatomy and Neurobiology

Medical College of Pennsylvania

Philadelphia, Pennsylvania 19169

${ }^{3}$ Institut National de la Santé et de la Recherche Médicale (INSERM)

U266-Centre National de la Recherche Scientifique (CNRS)

URA 1500, Faculté de Pharmacie

75270 Paris cedex 06, France

\begin{abstract}
We have previously reported that CCK-A receptor agonists and CCK-B receptor antagonists both enhance memory in an olfactory recognition test. Here, we report that the memory-enhancing effect of the CCK-B receptor antagonist L-365,260 (1 $\mathrm{mg} / \mathrm{kg}$ i.p.), but not that of the CCK-A receptor agonist caerulein $(0.03 \mathrm{mg} / \mathrm{kg}$ i.p.), was dramatically decreased following a bilateral transection of the perforant path, a principal source of input to the hippocampal formation. We further confirmed that a significant memory deficit occurred subsequent to this deafferentation of the hippocampus in untreated animals. In contrast, the effect of caerulein, but not that of L-365,260, was abolished following a bilateral subdiaphragmatic vagotomy. These results demonstrate that the hippocampal system plays a role in olfactory recognition and indicate that distinct neuronal pathways underlie the memory-enhancing effects of CCK-A and CCK-B drugs observed in the olfactory recognition test. The former effects (CCK-A) appear to involve a peripheral relay to the brain via the vagus
\end{abstract}

\footnotetext{
${ }^{1}$ Corresponding author.
}

nerve, whereas the latter (CCK-B) are directly central and involve, at least in part, the hippocampal system.

\section{Introduction}

The intense social investigatory behavior of male rats that invariably follows exposure to congeners represents a discriminative learning process for establishing individual recognition (Thor and Holloway 1982). This recognition, originally called social memory, is based on olfactory cues (Sawyer et al. 1984). The duration of investigatory behavior is a function of the degree of familiarity between the animals. Thus, when an adult male rat has briefly encountered a juvenile congener, the period of social investigation upon reexposure to the same individual is shorter, reflecting recognition of the juvenile, which is a memory process. The duration of investigation is an index of the decline of recognition when the delay between acquisition and recall increases. Recognition is specific of the familiar odor and is sensitive to interference (Thor and Holloway 1982; Dantzer et al. 1987). Performance on this olfactory recognition test is specifically modulated by cholinergic, GABA-ergic, and no-otropic drugs but not by psychostimulants (Perio et al. 1989).

In a previous set of experiments (Lemaire et al. 1992, 1994), we demonstrated that the endogenous neuropeptide cholecystokinin (CCK) could

LEARNING \& MEMORY 1:153-164 @ 1994 by Cold Spring Harbor Laboratory Press ISSN1072-0502/94 \$5.00

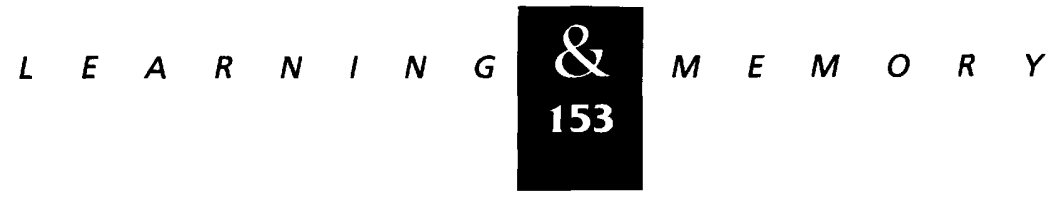


modulate olfactory recognition in opposite ways, depending on whether CCK-A or CCK-B receptors, the two receptor types that mediate the effects of CCK (Moran et al. 1986), were activated. Antagonists selective for the CCK-A receptors, such as devazepide, impair olfactory recognition, whereas antagonists selective for the CCK-B receptors, such as L-365,260, enhance it. Likewise, olfactory recognition is prolonged by the selective CCK-A receptor agonist compound $5 \mathrm{~b}$ [Boc-TrpLys(CO-NH-0-Tol)-Asp-Phe- $\mathrm{NH}_{2}$ ] (Shiosaki et al. 1991 ), by CCK-8 and by its analog caerulein, and shortened by the selective CCK-B agonists CCK-4 and BC 264 (Daugé et al. 1990). Thus, these results established that both CCK-A receptor agonists and CCK-B receptor antagonists have the potential to enhance memory.

CCK-B receptors are the dominant CCK-receptor type throughout the central nervous system (CNS) (Moran et al. 1986; Hill and Woodruff 1990), but they are particularly abundant in the entorhinal cortex and other parts of the hippocampal system (Köhler et al. 1987), that is, the hippocampal formation (Ammon's horn, dentate gyrus, and subicular complex) plus the interconnected cortical areas (entorhinal, perirhinal, and parahippocampal cortices). Electrophysiological studies have demonstrated the existence of functional CCK-B receptors in the hippocampal formation (Böhme et al. 1989; Bertrand et al. 1994). Moreover, abundant CCK immunoreactivity is present throughout the entorhinal cortex, hippocampal formation, and perforant path (PP) (Greenwood et al. 1981). Damage to each of these components of the hippocampal system produces memory deficits in humans, monkeys, and rats (for review, see Eichenbaum et al. 1992; Squire 1992). The PP in particular is thought to be a necessary link for the maintenance of the integrity of hippocampal system functioning (Myhrer 1988; Skelton and McNamara 1992; Jones 1993). We hypothesized that CCK-B receptor antagonists enhance olfactory recognition by directly acting on receptors in the entorhinal cortex, interfering with a signal to the hippocampus through the PP. Moreover, because relatively little is known about the anatomical pathways sustaining olfactory recognition, we also evaluated whether this particular process would be impaired in rats with a bilateral lesion of the PP. Such evidence of hippocampal system involvement in olfactory recognition would provide anatomical criterion to validate this test as a model of memory.
In contrast to CCK-B receptors, CCK-A receptors are mainly located in the gastrointestinal tract but also occur in discrete central areas, such as the nucleus tractus solitarius (NTS) and the area postrema (Moran et al. 1986; Hill and Woodruff 1990; Branchereau et al. 1992). Thus, the memory-enhancing effects of CCK-A receptor agonists on olfactory recognition may involve a neuronal pathway that is independent of the main entorhinal cortex-hippocampus circuit. In this regard, the vagus nerve, which contains both CCK-A and CCK-B receptors (Mercer and Lawrence 1992), may be responsible for relaying information from the periphery to the NTS. This nucleus projects, in turn, to limbic system-related structures, such as the frontal cortex, the septum, the amygdala, and the nucleus accumbens (Swanson 1983; Jean 1991). Vagotomy is known to block several CCK-A receptor-mediated responses to peripherally administered CCK, including memory enhancement (Flood and Morley 1989; Flood et al. 1992). Thus, a vagal relay may also be involved in the CCK-A receptor-mediated responses observed in the olfactory recognition test.

To test these hypotheses, we evaluated the influence of bilateral PP transection and bilateral subdiaphragmatic vagotomy on olfactory recognition, as well as their consequences on the memory-enhancing effects of a CCK-A receptor agonist and a CCK-B receptor antagonist.

\section{Materials and Methods}

\section{ANIMALS}

Male adult (300-450 grams) and juvenile (40-50 grams) Wistar rats were obtained from Iffa-Credo (Saint-Germain sur l'Arbresle, France). Adults were housed individually in the experimental room, and juveniles were housed in groups of five, in a separate maintenance room, in transparent plastic cages $(44 \times 29 \times 18 \mathrm{~cm})$ under a 6 a.m. -6 p.m. lighting schedule and controlled environment. Rats had free access to food and water, except during testing.

\section{SURGICAL PROCEDURES}

PP transections were performed according to an adaptation of the method of Cummings et al. (1992). Adult rats (300-350 grams) were anesthetized with $3 \mathrm{ml} / \mathrm{kg}$ (i.p.) of equithesin (a mixture

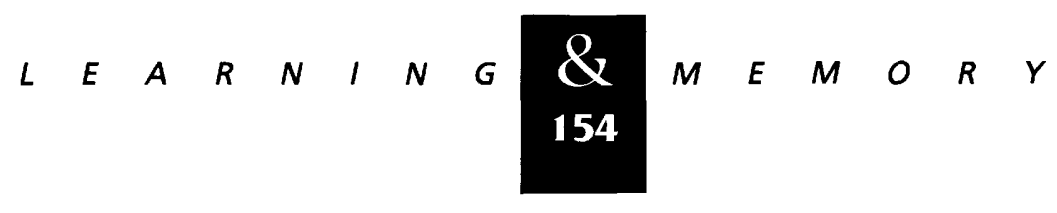


of chloral hydrate and pentobarbital) and placed in a Kopf stereotaxic frame with the incisor bar set at $-3.3 \mathrm{~mm}$. After drilling across the medial-lateral extent of the skull over the posterior cortex, lesions were made mechanically by cutting, starting $0.75 \mathrm{~mm}$ anterior to lambda and $4.1 \mathrm{~mm}$ lateral to midline. The knife (a specially made surgical blade $10 \mathrm{~mm}$ long, $0.6 \mathrm{~mm}$ wide, and $0.15 \mathrm{~mm}$ thick, with an edge angled $5^{\circ}$ from vertical) was repeatedly lowered $7.7 \mathrm{~mm}$ below the dorsal surface of the brain with a medial shift of $0.5 \mathrm{~mm}$ between each descent to make a coronal cut 2.5$\mathrm{mm}$ in total length. After the last descent, the blade was moved continuously across the $2.5-\mathrm{mm}$ extent of the lesion. After both right and left PPs were cut, the wound was sutured. Sham-operated rats were treated identically, except that the knife was lowered only $1.5 \mathrm{~mm}$ into the cortex. The rats were tested after 2 weeks postsurgical recovery. At the completion of testing, 12 lesioned rats and 5 shamoperated rats, randomly chosen, were sacrificed by decapitation. The brains were removed, frozen, and sectioned horizontally in $40-\mu \mathrm{m}$-thick slices (Jung CM 3000 microtome, Leica, Switzerland), and every tenth section was preserved. Sections were stained with cresyl violet. The location and extent of the transections were confirmed using the stereotaxic atlas of Paxinos and Watson (1986).

Vagotomies (VGX) were performed by an external experienced laboratory (Iffa-Credo). VGX was made bilaterally at the subdiaphragmatic level on adult rats (400-450 grams) fasted for $24 \mathrm{hr}$. Rats were anesthetized with $75 \mathrm{mg} / \mathrm{kg}$ (i.m.) of Imalgene (Pasteur) and $5 \mathrm{mg} / \mathrm{kg}$ (i.p.) of Valium (Roche). A midline laparotomy was performed and the stomach was gently extracted, exposing the lower thoracic esophagus. The left and right vagal trunks were then exposed and excised. The tract was then replaced and the wound sutured. For sham-operated rats, the procedure was identical, except that the vagal nerves were not cut. The thoroughness of the VGX was checked by a postmortem examination of control rats, in which the volume of the stomach was observed to be substantially augmented. The rats were tested beginning 3 weeks postsurgery.

Two sets of 12 PP-lesioned and 12 sham-operated rats were performed. Animals of the first set were used to test the influence of PP lesion per se on olfactory recognition and on the memory-enhancing effect of L-365,260. Two PP-lesioned rats died before the completion of the behavioral test- ing, and these results were thus discarded from the entire experiment. Animals of the second set were used to test the influence of PP lesion per se on olfactory recognition and olfactory discrimination, and on the memory-enhancing effect of caerulein. Four sets of $10 \mathrm{VGX}$ and 10 sham-operated rats were performed. Animals of the two first sets were used to test the influence of VGX per se on olfactory recognition. Animals of the third and fourth sets were used to test the influence of VGX on the memory-enhancing effect of L-365,260 and caerulein, respectively.

\section{BEHAVIORAL PROTOCOLS}

OLFACTORY RECOGNITION

The procedure for evaluating olfactory recognition has been described previously (Lemaire et al. 1992, 1994). Briefly, $\sim 1 \mathrm{hr}$ before the start of the test, the juveniles were brought into the experimental room and placed individually in small cages $(44 \times 14 \times 14 \mathrm{~cm})$ to isolate their odors. The adult was exposed twice for $5 \mathrm{~min}$, in its home cage, to the same juvenile congener, at a time interval of 30 or $120 \mathrm{~min}$. During both encounters, the time the adult spent investigating the juvenile (sniffing, grooming, closely following) was measured. Under such conditions, the ability of control rats to recognize the juvenile by olfactory cues lasts for $<1 \mathrm{hr}$ : Recognition manifests itself as a reduced duration of investigatory behavior upon reexposure, after a 30-min time interval; lack of recognition manifests itself as an unmodified duration of investigation upon reexposure, after a 120-min time interval. Thus, the memory deficits induced by the lesions resulted in a persistence in the investigation duration when the two exposures were separated by $30 \mathrm{~min}$; and the memoryenhancing effects of the drugs resulted in a decreased investigation duration when the two exposures were separated by $120 \mathrm{~min}$. For all pharmacological tests, the drugs were injected i.p. $(1 \mathrm{ml} / \mathrm{kg}$ ) immediately after the initial encounter. L-365,260 and caerulein were administered at doses of 1 and $0.03 \mathrm{mg} / \mathrm{kg}$, respectively, at which these compounds had been found previously to enhance olfactory recognition in unoperated rats (Lemaire et al. 1992, 1994). Animals were their own controls, that is, they received both the vehicle and the drug. Half of the animals in each surgery group first received the vehicle and then the

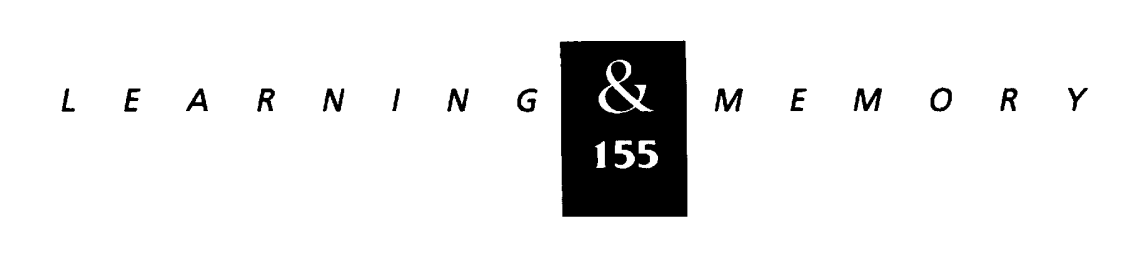


Lemaire et al.

drug 1 week later. The other half of the rats received the treatments in the opposite order. In addition, in PP-lesioned rats, we tested whether L-365,260 and caerulein restored recognition when the two encounters were separated by 30 min. We tested also for side effects of caerulein in PP-lesioned rats, by presenting to the adult a juvenile, previously unmet, $120 \mathrm{~min}$ after the first encounter.

\section{OLFACTORY DISCRIMINATION}

The procedure used to evaluate olfactory sensory functions was based on that of Carr et al. (1976). The adults were exposed for $5 \mathrm{~min}$, in their home cage, to two small boxes, one filled with juveniles' soiled bedding (novel odor), the other with its own soiled bedding (familiar odor). The arrangement of the boxes at the left and right side of the cage was counterbalanced to avoid spatial bias. The time the adult spent sniffing each box was measured. Control rats were able to discriminate between the two odors and sniffed the box containing the juveniles' bedding for a longer time than the box with their own bedding; this has been termed "preference" for the novel odor.

\section{DRUGS}

L-365,260 [3R-( + )-N-(2,3-dihydro-1-methyl2-oxo-5-phenyl-1H-1,4-benzodiazepin-3yl) $N^{1}$-(3methyl-phenyl)urea], synthesized in the Medicinal Chemistry Department of Rhône-Poulenc Rorer S.A., was suspended in water containing $1 \%$ (vol/ vol) of polysorbate. Caerulein [Pyr-Gln-Asp-Tyr$\left(\mathrm{SO}_{3} \mathrm{H}\right)$-Thr-Gly-Met-Asp-Phe- $\mathrm{NH}_{2}$, Bachem, Switzerland] was dissolved in saline to obtain a stock solution of $0.03 \mathrm{mg} / \mathrm{kg}$. This solution was divided into 1-ml aliquots, stored at $-20^{\circ} \mathrm{C}$, and maintained on ice during use.

\section{DATA PRESENTATION AND STATISTICS}

To assess olfactory recognition, the ratio of investigation duration (RID) of the second to the first encounter was calculated for each rat, following Perio et al. (1989) and others (Popik and Van Ree 1991; Hlinak and Krejci 1992; Kan et al. 1993). This transformation is used to minimize interindividual variability. The RID values express the variation of the duration of investigation be- tween the two encounters and are therefore a measure of olfactory recognition (RID of 1 indicates lack of recognition; lower scores of RID reflect better recognition).

Olfactory discrimination was assessed by determining, for each subject, an olfactory discrimination index (ODI), defined as follows: ODI = (novel odor sniffing duration - known odor sniffing duration $) /($ total sniffing duration $) \times 100$. These ODI values express the preference for the novel odor, thereby representing the ability of the rat to discriminate between the two odors (ODI of $0 \%$ indicates lack of preference; ODI scores $>0 \%$ indicate discrimination).

ODI and RID values, because of their nonGaussian distribution, were subjected to nonparametric statistical analyses. Paired Wilcoxon or unpaired Mann-Whitney tests were used, according to the experimental design. However, to make the text and the figures more legible, the means \pm S.E.M., instead of medians and interquartile range, are presented.

\section{Results}

\section{HISTOLOGY OF THE PP LESIONS}

Histological examination, using the atlas of Paxinos and Watson (1986), confirmed that the knife cuts were located at the rostrocaudal level of the subiculum and that they transected bilaterally the PP in its entire dorsoventral extent in all 12 PP-lesioned rats studied (Fig. 1). Only lesions of the overlying visual cortex were observed in the five sham-operated rats examined.

\section{BILATERAL LESION OF THE PP, BUT NOT BILATERAL SUBDIAPHRAGMATIC VGX, ABOLISHES OLFACTORY RECOGNITION}

Figure 2 shows the RID for VGX and PP-lesioned rats, and for sham-operated rats, when the two encounters were separated by $30 \mathrm{~min}$. Impaired olfactory recognition is thus evident as an augmentation in RID (see Materials and Methods). For each surgical condition, two separate experiments were done.

The durations of investigation at the initial encounter for PP-lesioned rats and control rats were $94.3 \pm 7.5 \sec (n=10)$ versus $77.2 \pm 9.2 \mathrm{sec}(n$ $=12$ ), respectively, in the first experiment ( $t=$

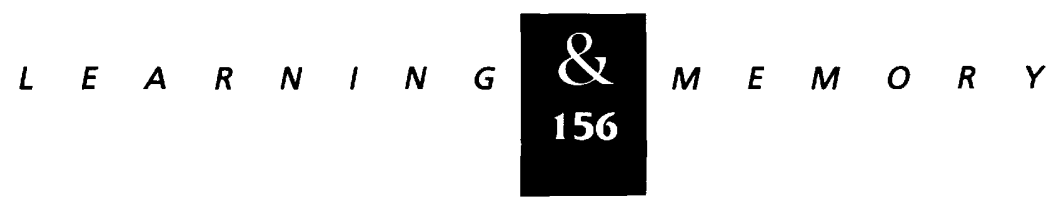




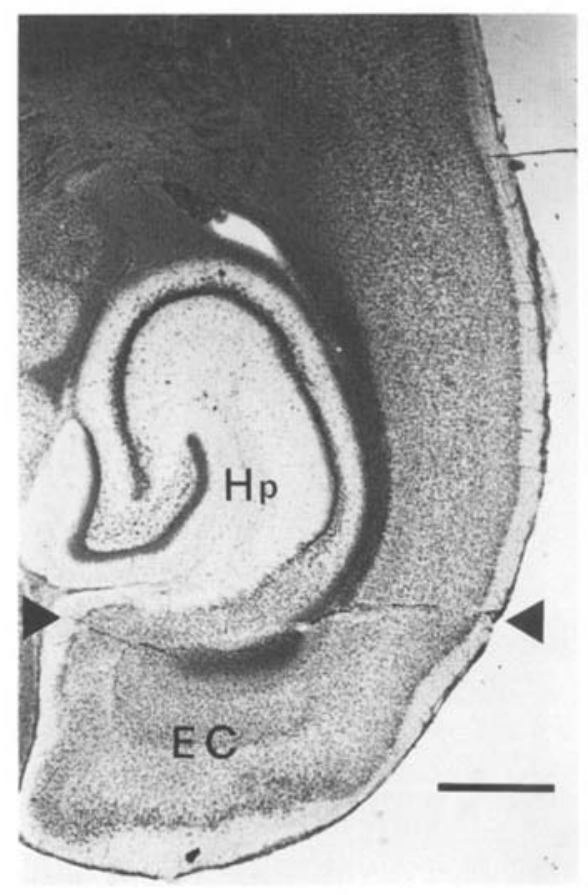

Figure 1: Photomicrograph of a horizontal section representative of the knife cut of the PP. Note that the lesion (arrowheads) disconnected the entorhinal cortex (EC) from the hippocampus $(\mathrm{Hp})$. Bar, $1 \mathrm{~mm}$.

1.44, $P>0.16),{ }^{1}$ and $118.4 \pm 7.1 \mathrm{sec}(n=12)$ versus $126.3 \pm 7.6 \mathrm{sec}(n=12)$, respectively, in the second experiment $(t=0.76, P>0.45)$. The data for VGX rats and their controls were, respectively, $95.4 \pm 7.4 \mathrm{sec}(n=10)$ versus $90.7 \pm 13.0$ $\sec (n=10)$ in the first experiment $(t=0.31$, $P>0.75)$, and $125.9 \pm 9.0 \mathrm{sec}(n=10)$ versus $103.8 \pm 7.6 \sec (n=10)$ in the second experiment $(t=1.89, P>0.07)$. Thus, neither the PP lesion nor the VGX altered the duration of investigation of an unfamiliar juvenile.

In contrast to sham-operated rats, PP-lesioned rats tended not to recognize a juvenile they had met 30 min earlier (Fig. 2A). In both experiments their RID was increased significantly. For experiment $1, U=23.5, P<0.014$, Mann-Whitney unpaired test, PP-lesioned rats versus sham-operated rats and for experiment $2, U=17.5, P<0.001$. Rats of the second experiment were also used to study the influence of the PP lesion on olfactory discrimination. In the olfactory discrimination test

'Because the durations of investigation followed a Gaussian distribution, the means were compared by using a twotailed Student t-test.

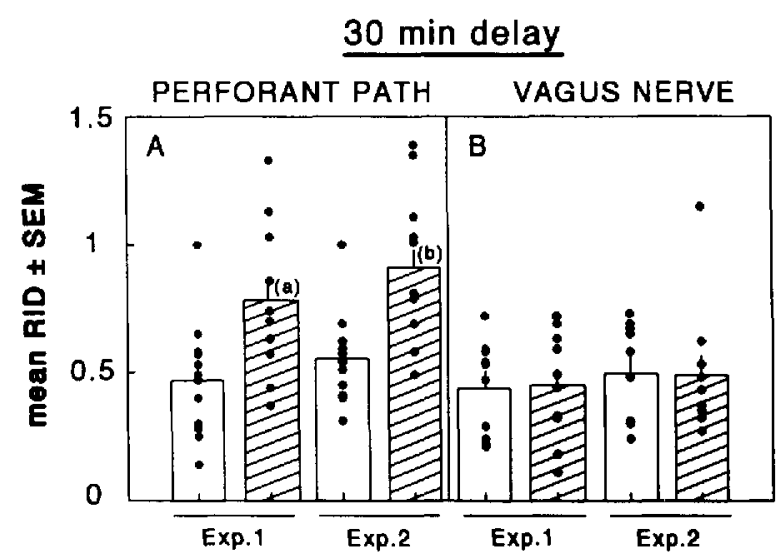

Figure 2: Effect of PP transection ( $A$ ) and vagotomy $(B)$ on olfactory recognition. Data illustrated are means \pm S.E.M. RID (vertical bars) and the corresponding individual RID (circles) for sham-operated (blank columns) and lesioned (hatched columns) rats. (a) $P<0.05$; (b) $P<$ 0.001 , Mann-Whitney unpaired test, lesioned rats vs. respective sham-operated control rats. $n=10$, except for the two groups of sham PP-lesioned rats and the group of PP-lesioned rats of the second experiment $(n=$ 12). Note that the PP transection, but not the vagotomy, impaired olfactory recognition. These experiments were performed twice (Exp. 1 and Exp. 2).

(Table 1), sham-operated and PP-lesioned rats spent a similar amount of time sniffing the two boxes $(116.3 \pm 7.9 \mathrm{sec}$ and $133.1 \pm 6.7 \mathrm{sec}$, respectively, $t=1.63, P>0.11){ }^{2}$ They also equally preferred the novel to the known odor, as their ODI values were identical $(U=69.0, P>0.8)$. The PP lesion therefore did not affect the attraction of the rats to investigate odorants or their sensory discrimination capacity.

The VGX had no apparent effect on olfactory recognition (Fig. 2B). The RID of sham-operated rats $(n=10)$ and VGX rats $(n=10)$ were not different either in the first $(U=47.0, P>0.8)$ or in the second experiment $(U=46.5, P>0.8)$.

\section{EFFECT OF THE PP LESION AND VGX ON MEMORY ENHANCEMENT INDUCED BY CCK-ERGIC DRUGS}

In these studies rats were their own control. Therefore, individual performances are repre-

\footnotetext{
${ }^{2}$ Because the durations of sniffing followed a Gaussian distribution, the means were compared by using a two-tailed Student $t$-test.
} 
Lemaire et al.

Table 1: Olfactory discrimination in $P P$-lesioned rats

\begin{tabular}{lcc}
\hline $\begin{array}{c}\text { Time spent sniffing } \\
\text { (sec) }\end{array}$ & Sham & PP \\
\hline Familiar odor & $40.3 \pm 3.7$ & $46.2 \pm 4.5$ \\
Unfamiliar odor & $76.0 \pm 5.1$ & $86.9 \pm 4.1$ \\
ODI (\%) & $31.0 \pm 3.5$ & $31.5 \pm 4.3$ \\
\hline
\end{tabular}

sented in Figure 3 by points defined by the RID obtained for a given rat after vehicle treatment ( $x$-axis) versus the RID obtained for the same rat after drug treatmen $\mathrm{t}(y$-axis). Thus, the bissectrix represents no drug effect $(x=y)$, and the memory-enhancing effect of the drug for each rat is visualized as points situated under the bissectrix $(y<x)$. Figure 4 shows the mean RID for each surgery group and each drug condition, when the two encounters were separated by $120 \mathrm{~min}$. En-

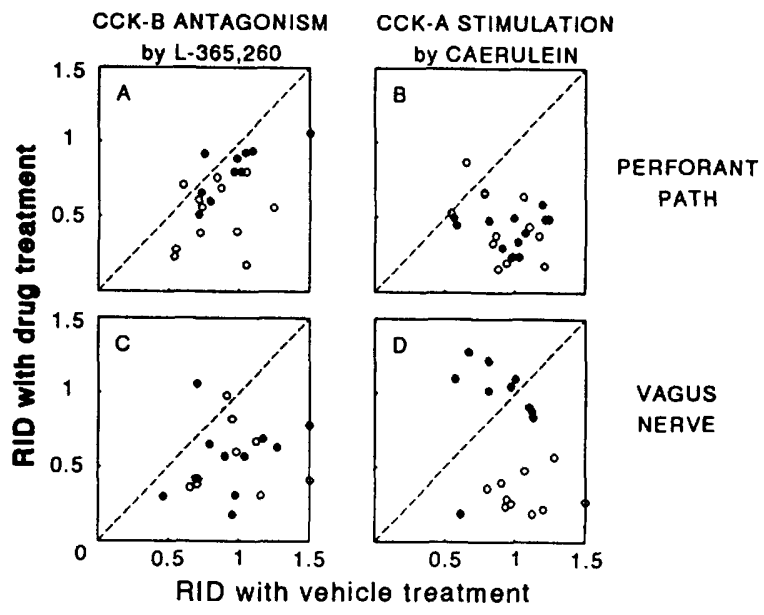

Figure 3: Effect of PP transection $(A, B)$ and vagotomy $(C, D)$ on olfactory recognition enhancement induced by L-365,260 [1 mg/kg (i.p.)] $(A, C)$ and caerulein $[0.03$ $\mathrm{mg} / \mathrm{kg}$ (i.p.)] $(B, D)$. The performances of each lesioned rat $(O)$ and each sham-operated rat $(O)$ at 120 min delay are represented by a point defined by coordinates consisting of the RID obtained after drug treatment for a given rat vs. the RID obtained after vehicle treatment for the same rat. Points under the bissectrix represent memory enhancement. The influence of the PP lesion on the effects of L-365,260 and caerulein was tested with the rats used for the first and the second experiment presented in Fig. 2, respectively. The influence of vagotomy was tested with different groups of sham-operated and vagotomized rats ( $n=10$, for all four groups).

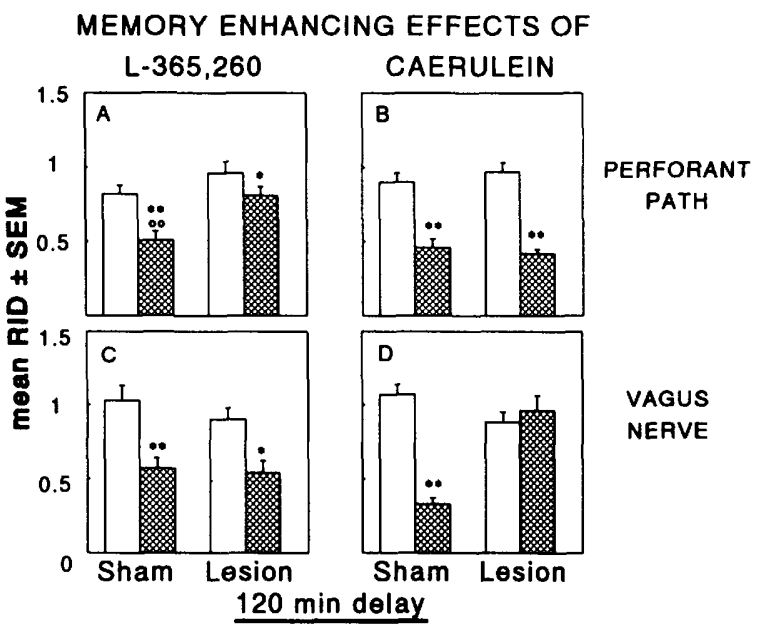

Figure 4: Effect of PP transection $(A, B)$ and vagotomy $(C, D)$ on olfactory recognition enhancement induced by L-365,260 [1 mg/kg (i.p.)] (A,C) and caerulein [0.03 $\mathrm{mg} / \mathrm{kg}$ (i.p.)] $(B, D)$. Data illustrated are means \pm S.E.M. RID for sham-operated and lesioned rats after vehicle treatment (open bars) and drug treatment (cross-hatched bars). $\left(^{*}\right) P<0.05 ;\left({ }^{* *}\right) P<0.01$, Wilcoxon paired test, drug treatment vs. respective vehicle treatment. $(\mathrm{O})$ $P<0.01$, Mann-Whitney unpaired test, lesioned rats vs. sham-operated rats. The different groups of rats presented here and in Fig. 3 are the same (for details, see legend). Note that PP transection reduced the facilitatory effect of the CCK-B receptor antagonist L-365,260 on olfactory recognition but not that of the CCK-A receptor agonist caerulein. On the contrary, vagotomy blocked the facilitatory effect of caerulein, but not that of L-365, 260 .

hanced olfactory recognition is thus evident as a decrease in RID (see Materials and Methods).

HIPPOCAMPAL DEAFFERENTATION ATTENUATES FACILITATORY EFFECT MEDIATED BY A CCK-B RECEPTOR ANTAGONIST, BUT NOT THAT MEDIATED BY A CCK-A RECEPTOR AGONIST

The PP-lesioned rats that had been used for the first and second experiments were used to study the influence of the PP lesion on the effect of L-365,260 and caerulein, respectively.

In sham-operated rats, $\mathrm{L}-365,260$ at $1 \mathrm{mg} / \mathrm{kg}$ (i.p.) prolonged olfactory recognition such that it lasted for $120 \mathrm{~min}$, leading to a highly significant decrease of the $\operatorname{RID}^{3}(W=2.82, P<0.005$,

${ }^{3}$ The raw data corresponding to the RID were as follows: For sham-operated rats treated with vehicle, $75.8 \pm 8.5 \mathrm{sec}$

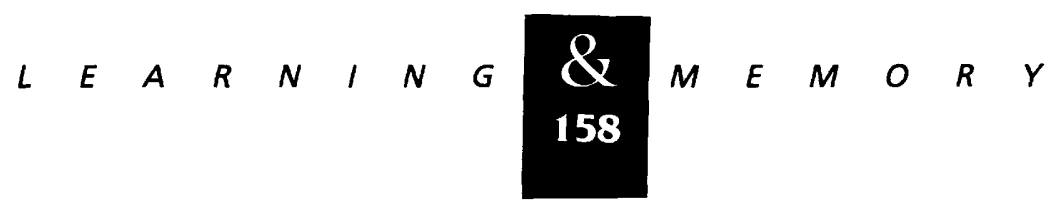


Wilcoxon paired test, drug treatment versus vehicle treatment; Fig. 4A). The same treatment led to a slight, though also significant, decrease of the RID in PP-lesioned rats $(W=2.19, P<0.029)$. However, in Figure 3A the individual data points corresponding to sham-operated rats lie well below the bissectrix, whereas the points corresponding to the PP-lesioned rats are closer to it. Thus, the PP lesion appeared to attenuate the memoryenhancing effect of L-365,260. Statistical analysis confirmed this trend: The RID of PP-lesioned rats treated with L-365,260 were significantly higher than those of L-365,260-treated sham-operated rats $(U=17.0, P<0.004$; Fig. 4A). Moreover, when the time interval between encounters was reduced to $30 \mathrm{~min}, \mathrm{~L}-365,260$ still did not restore normal performance in PP-lesioned rats: The RID remained significantly higher than those obtained for sham-operated rats (RID $=0.42 \pm 0.06$ and $0.73 \pm 0.08$, for sham-operated and PP-lesioned rats, respectively; $U=20.0, P<0.008$ ).

In contrast to the apparent attenuation of the activity of L-365,260 induced by the PP transection, this lesion was virtually without influence on the memory-enhancing activity of caerulein at $0.03 \mathrm{mg} / \mathrm{kg}$ (i.p): The distribution of the individual data points of both groups was homogeneous and the points were situated at a distance from the bissectrix (Fig. 3B). Thus, caerulein significantly decreased the RID ${ }^{4}$ in both sham-operated and PPlesioned rats $(W=2.746, P<0.006$ and $W=$ 3.059, $P<0.003$, respectively; Fig. $4 \mathrm{~B}$ ). This decrease was specific to recognition of the previously met juvenile, because caerulein did not significantly decrease the RID of either sham-operated $(1.02 \pm 0.08$ and $0.89 \pm 0.08 ; W=1.023$, $P>0.3)$ or PP-lesioned rats $(0.97 \pm 0.09$ and 0.89 $\pm 0.08 ; W=0.078, P>0.9)$ presented with a

and $66.2 \pm 10.3 \mathrm{sec}$ durations of investigation at the first and second encounter, respectively; for sham-operated rats treated with $1 \mathrm{mg} / \mathrm{kg}$ of L-365,260, 73.8 $\pm 8.0 \mathrm{sec}$ and $42.6 \pm 8.5 \mathrm{sec}$, respectively; for PP-lesioned rats treated with vehicle, $90.8 \pm$ $11.3 \mathrm{sec}$ and $85.9 \pm 11.1 \mathrm{sec}$, respectively; for PP-lesioned rats treated with $1 \mathrm{mg} / \mathrm{kg}$ of L-365,260, $95.9 \pm 8.8 \mathrm{sec}$ and $77.3 \pm$ $7.9 \mathrm{sec}$, respectively.

${ }^{4}$ The raw data corresponding to the RID were as follows: for sham-operated rats treated with vehicle, $119.0 \pm 9.3 \mathrm{sec}$ and $105.9 \pm 10.0 \mathrm{sec}$ durations of investigation at the first and second encounter, respectively; for sham-operated rats treated with $0.03 \mathrm{mg} / \mathrm{kg}$ of caerulein, $114.8 \pm 7.6 \mathrm{sec}$ and $51.2 \pm 7.4$ $\mathrm{sec}$, respectively; for PP-lesioned rats treated with vehicle, $103.1 \pm 6.6 \mathrm{sec}$ and $100.7 \pm 10.1 \mathrm{sec}$, respectively; for PPlesioned rats treated with $0.03 \mathrm{mg} / \mathrm{kg}$ of caerulein, $116.8 \pm 6.1$ $\mathrm{sec}$ and $48.4 \pm 4.3 \mathrm{sec}$, respectively. previously unmet juvenile $120 \mathrm{~min}$ after the first encounter. At a shorter interval (30 min), caerulein had obvious hypolocomotor effects, which decreased the investigatory behavior not only of a familiar, but also of an unfamiliar, juvenile, and therefore impeded any interpretation of the results in terms of memory effects. Thus, testing the capability of caerulein to restore memory in PPlesioned rats was interrupted before its completion.

BILATERAL SUBDIAPHRAGMATIC VGX BLOCKS FACILITATORY EFFECT MEDIATED BY A CCK-A RECEPTOR AGONIST, BUT NOT THAT MEDIATED BY A CCK-B RECEPTOR ANTAGONIST

In contrast to PP lesions, VGX appeared to be devoid of influence on the memory-enhancing effect of L-365,260. As shown in Figure 3C, there is a similar distribution of the individual data points of both groups well away from the bissectrix. Statistical analysis confirmed this finding: L-365,260 significantly prolonged olfactory recognition such that it lasted for at least $120 \mathrm{~min}$ in both shamoperated and VGX rats, as shown by a significant decrease of the $\operatorname{RID}^{5}(W=2.701, P<0.007$ and $W=2.293, P<0.03$, for sham-operated and VGX rats, respectively; Fig. 4C).

In contrast to that of L-365,260, the memoryenhancing effect of caerulein was completely blocked by vagotomy. This is shown in the striking difference in distribution of the individual data points of sham-operated rats and VGX rats (Fig. 3D). The treatment significantly decreased the RID $^{6}$ of sham-operated rats $(W=2.803, P<$

\footnotetext{
${ }^{5}$ The raw data corresponding to the RID were as follows: for sham-operated rats treated with vehicle, $88.8 \pm 6.4 \mathrm{sec}$ and $93.0 \pm 12.4 \mathrm{sec}$ durations of investigation at the first and second encounter, respectively; for sham-operated rats treated with $1 \mathrm{mg} / \mathrm{kg}$ of L-365,260, $97.5 \pm 11.1 \mathrm{sec}$ and $56.6 \pm 10.7$ sec, respectively; for VGX rats treated with vehicle, $105.1 \pm$ $9.0 \mathrm{sec}$ and $93.4 \pm 9.8 \mathrm{sec}$, respectively; for VGX rats treated with $1 \mathrm{mg} / \mathrm{kg}$ of L-365,260, $110.0 \pm 8.7 \mathrm{sec}$ and $61.2 \pm 10.7$ sec, respectively.

${ }^{6}$ The raw data corresponding to the RID were as follows: for sham-operated rats treated with vehicle, $79.5 \pm 7.5 \mathrm{sec}$ and $84.2 \pm 8.5 \mathrm{sec}$ durations of investigation at the first and second encounter, respectively; for sham-operated rats treated with 0.03 $\mathrm{mg} / \mathrm{kg}$ of caerulein, $105.0 \pm 6.9 \mathrm{sec}$ and $34.2 \pm 4.4 \mathrm{sec}$, respectively; for VGX rats treated with vehicle, $94.2 \pm 8.7 \mathrm{sec}$ and 84.6 $\pm 10.8 \mathrm{sec}$, respectively; for VGX rats treated with $0.03 \mathrm{mg} / \mathrm{kg}$ of caerulein, $78.9 \pm 8.4 \mathrm{sec}$ and $72.6 \pm 9.5 \mathrm{sec}$, respectively.
}

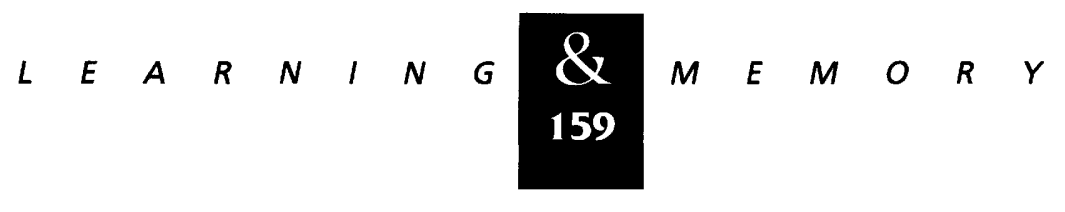


Lemaire et al.

0.006 ), but not those of VGX rats ( $W=0.561$, $P>0.5$; Fig. 4D).

\section{Discussion}

The present results demonstrate that the enhancing effects of CCK-A receptor agonists and CCK-B receptor antagonists on olfactory memory depend on different neuronal pathways. CCK-B receptor-mediated responses appear to be of direct central origin and to involve, at least partially, entorhinal cortex-hippocampus connections. In contrast, CCK-A receptor-mediated responses, insensitive to the lesion of the PP, have a peripheral origin and involve an obligatory central relay (NTS) through the vagus nerve. These results also indicate that hippocampal deafferentation impairs olfactory recognition, providing an important anatomical validation of the olfactory recognition test as a model of memory and adding to the types of memory tasks sensitive to PP lesion (e.g., Skelton and McNamara 1992).

\section{HIPPOCAMPAL SYSTEM AND OLFACTORY RECOGNITION TEST}

The olfactory recognition test used here has been conceptually (Thor and Holloway 1982; Dantzer et al. 1987) and pharmacologically (Perio et al. 1989) validated and subsequently applied by several investigators, including ourselves, as a model of memory for pharmacological studies (e.g., Hlinak and Krejci 1992; Popik et al. 1992; Böhme et al. 1993; Kan et al. 1993). However, there has been a lack of information concerning the anatomical substrates involved in olfactory recognition.

There is considerable evidence for the involvement of the hippocampal system in specific kinds of memory processes in rodents, monkeys, and humans (for review, see Eichenbaum et al. 1992; Squire 1992). The PP, as the principal link between the entorhinal cortex and the hippocampal formation, is crucial for the integrity of hippocampal functioning (Jones 1993). Disruption of olfactory recognition following bilateral transection of the PP is thus evidence for hippocampal dependence of olfactory-guided behavior. Moreover, in addition to the main cortical afferents provided by the PP, the hippocampal formation receives important modulatory input via the cholin- ergic septohippocampal pathway (Gaykema et al. 1990). Terranova et al. (1994) have shown recently that a lesion of the septum also disrupts olfactory recognition, further supporting the hippocampal dependence and the mnemonic nature of this process.

The entorhinal cortex integrates information from a large variety of sensory modalities and conveys it to the hippocampal formation via the PP. The major source of inputs to the entorhinal cortex are the perirhinal and parahippocampal cortices, which receive convergent inputs from a variety of unimodal and polymodal association areas (Suzuki and Amaral 1994). In addition, the entorhinal cortex receives a direct input from the olfactory bulb (Scalia and Winans 1975). Thus, the deficit in olfactory recognition behavior that we observed following damage to the PP may reflect a general defect in olfactory sensory function rather than a specific impairment of memory processes. However, this possibility appears unlikely, as discriminative olfactory ability is not altered in PPlesioned animals (Table 1). As do sham-operated rats, PP-lesioned animals clearly prefer the odor of the juveniles to their own, indicating intact sensory discrimination.

The entorhinal cortex and its connections to the hippocampus participate in control of emotional states (Swanson 1983). Social investigation among rats is influenced by the emotional state of the animals (File 1985): In an anxiogenic environment, social investigation is reduced dramatically. Anxiolytic drugs prevent this decrease. Therefore, the persistent duration of investigation that we observed in PP-lesioned rats at the second encounter could reveal an anxiolytic-like effect of the lesion. However, when the animals were presented with a juvenile in an anxiogenic environment (unknown testing-cage and strong illumination), the duration of investigation was decreased as much in PP-lesioned rats as in control rats, compared with the duration of investigation in a familiar environment (C. Pauchet, pers. comm.).

On the other hand, it has been reported that $\mathrm{PP}$ lesions decrease preference for novelty ( $\mathrm{My}$ hrer 1988). In our paradigm, such an effect could have led to a reduced motivation or curiosity for the juvenile and, consequently, to a failure to acquire memory. However, we found that PP lesions altered neither the duration of investigation of a juvenile at the first encounter (see Results) nor the duration of sniffing of a novel odor (Table 1). Therefore, transection of the PP does not seem

$$
\begin{array}{lllllllllllllll}
\mathcal{Q} & E & A & R & N & I & N & G & \begin{array}{c}
\boldsymbol{X} \\
160
\end{array} & M & E & M & O & R & Y
\end{array}
$$


likely to cause an attentional or motivational deficit. Moreover, the deficit in olfactory recognition in PP-lesioned animals can be overcome by a pharmacological treatment (caerulein) administered after the acquisition phase (first encounter). This confirms that the information has been acquired and suggests that the deficit observed at the retention phase (second encounter) probably involves processes of memory consolidation. This finding also suggests that even if the PP is necessary for the normal processing of olfactory recognition, the deficit caused by the PP lesion can be compensated for by the recruitment of other modulatory pathways. Terranova et al. (1994) showed similarly that cholinergic drugs can compensate for olfactory recognition deficits induced by septal damage.

Taken together, the results demonstrate that the olfactory recognition test is a reliable model of memory, which can be used in pharmacological studies.

\section{CCK AND OLFACTORY MEMORY}

The involvement of CCK in learning and memory has been shown using mainly active and passive avoidance tests (for review, see Itoh and Lal 1990) and generally has not addressed the participation of CCK-A and CCK-B receptors. In the olfactory recognition test used here, we demonstrated opposite effects of CCK-A and CCK-B receptor stimulation. We found previously that CCK-A receptor agonists (Lemaire et al. 1994) and CCK-B receptor antagonists (Lemaire et al. 1992) both enhance memory in intact rats. Here, we have confirmed these results by experiments with sham-PP-lesioned and sham-VGX rats, and we have extended them by showing that this enhancement of memory is supported by distinct neuronal pathways. We found that transection of the PP does not affect the memory-enhancing effect of caerulein, which is mediated by CCK-A receptors, whereas it dramatically reduces the memory-enhancing effect of the CCK-B receptor antagonist L-365,260. On the contrary, a subdiaphragmatic vagotomy does not affect the memory-enhancing effect of L-365,260 but fully blocks that of caerulein. These results can be examined in the context of the distribution of CCK receptors. CCK-A receptors are mainly situated in the periphery (especially the gastrointestinal tract) but also occur in the NTS and the area postrema. CCK-B recep- tors are widely distributed throughout the brain (Moran et al. 1986; Hill and Woodruff 1990); at the peripheral level, their distribution follows that of the gastrin receptors to which they are identical (Lee et al. 1993). The extensive distribution of both CCK-A and CCK-B receptors raises several questions. First, are the behavioral effects observed after peripheral administration of CCK-ergic ligands of central origin or do they result from signals elicited at the periphery and transmitted indirectly to the CNS? Second, which central structures and relay pathways are involved in this transmission? The results presented here address these issues.

The vagus nerve, which contains both CCK-A and CCK-B receptors (Mercer and Lawrence 1992), is a good candidate for relaying information from the periphery to the NTS, a structure that also contains functional CCK-A and CCK-B receptors (Branchereau et al. 1992). We found that the behavioral response to caerulein, indicative of memory enhancement, was fully abolished when the vagus nerve was cut. This indicates that the CCK-A receptor-mediated effect of this compound on olfactory recognition is primarily relayed, from the periphery to the brain, by the vagus nerve projecting to the NTS, the main central area where CCK-A receptors are detected by autoradiography (Moran et al. 1986; Hill and Woodruff 1990). Interestingly, we have noted that fasting impairs olfactory recognition in control rats but not in VGX rats (M. Lemaire, G.A. Böhme, O. Piot, P. Barnéoud, J.C. Blanchard, unpubl.). The memory-enhancing effect of endogenous CCK released by feeding is also a CCK-A receptor-mediated effect transmitted by vagal afferents to the NTS (Flood and Morley 1989; Flood et al. 1992). This nucleus sends direct or indirect projections to the amygdala, via the stria terminalis and bed nucleus. These investigators concluded that the final step responsible for memory enhancement may be a shift of the balance between the opioidergic and noradrenergic systems away from the former. A similar mechanism may also underlie the effect of caerulein on olfactory recognition. On the other hand, caerulein still enhances olfactory recognition if the PP is damaged. It is well recognized that caerulein induces hypolocomotor and anxiogeniclike effects (see Vasar et al. 1994). In our paradigm, such effects lead to a reduction of the investigation duration not only of a familiar, but also of an unfamiliar, juvenile, presented $30 \mathrm{~min}$ after the treatment. Thus, we were not able to test the

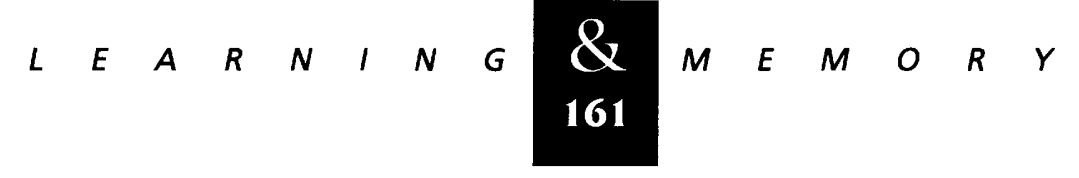


memory-restoring effect of caerulein in PP-lesioned rats. These side effects are, however, transitory, and the investigation duration of a familiar, but not of an unfamiliar, juvenile is decreased 120 min after the administration of caerulein in shamoperated rats. The persistence of the effect of caerulein in PP-lesioned rats is not the result of a higher sensitivity to unspecific effects of the drug as in these animals, caerulein did not alter the duration of investigation of an unfamiliar juvenile. Thus, the memory-enhancing effect of caerulein can compensate for the memory deficit induced by the lesion and involves a neuronal pathway independent of the PP. However, because the NTS is directly connected to numerous other limbic structures, such as the frontal cortex, the septum, the amygdala, and the nucleus accumbens, also known to be important in memory processes (Swanson 1983; Jean 1991), we could not, on the basis of our present results, determine whether the neuronal circuitry sustaining CCK-A receptormediated memory enhancement is totally independent of the hippocampal system or whether it involves part of the hippocampal system, downstream to the PP projections.

The vagus nerve transmits a number of the CCK-A receptor-mediated effects observed when CCK is administered peripherally, including satiety and the associated behavioral syndrome (Crawley et al. 1981; Smith et al. 1981), hypolocomotion (Itoh and Katsuura 1986), and memory enhancement (Flood and Morley 1989; Flood et al. 1992). Recently, Vasar et al. (1994) reported that VGX alters CCK-A receptor-mediated effects on locomotor activity but not CCK-B receptor-mediated effects on exploration. We found here that VGX also alters the effects on olfactory recognition mediated by the CCK-A receptors but not those mediated by the CCK-B receptors. Similarly, the amnesic effect of a CCK-A receptor antagonist on olfactory recognition is blocked by VGX, whereas that of a CCK-B receptor agonist is not (M. Lemaire, G.A. Böhme, O. Piot, P. Barnéoud, and J.C. Blanchard, unpubl.). Therefore, although both receptor types are present and functional in the NTS (Branchereau et al. 1992; Mercer and Lawrence 1992), to our knowledge, only the CCK-A receptor-mediated responses are relayed via the vagus nerve from the periphery to the CNS.

The persistence of the memory-enhancing effect of L-365,260 after VGX suggests that this compound acts directly on CCK-B receptors inside the brain. Alternatively, L-365,260 may act at the level of the area postrema, a circumventricular area interconnected with the NTS that responds to circulating CCK (Johnson and Gross 1993). The effects triggered by L-365,260 may involve multiple brain regions, given the widespread distribution of CCK-B receptors throughout the CNS (Moran et al. 1986; Hill and Woodruff 1990). However, the hippocampal system is particularly rich in CCK-B receptors (Köhler et al. 1987) and in CCK-like immunoreactivity (Greenwood et al. 1981). Based on our observation that the memory-enhancing effect of L-365,260 was sensitive to the PP lesion, we suggest that this pathway is a primary target for the central effects of this drug. In addition, L-365,260 is unable to restore normal responses in PP-lesioned rats when the interval between the two encounters is shortened from 120 to $30 \mathrm{~min}$ (see Results). Yet, olfactory recognition in PP-lesioned rats remains sensitive to drug manipulation (i.e., by caerulein), confirming that the absence of effect of $L-365,260$ is not the result of an insurmountable memory deficit but to the disruption of a neuronal pathway, the functioning of which is necessary for the mnemonic effect of L-365,260. It could be argued that because different sets of rats were used to evaluate the influence of the PP lesion on the effects of L-365,260 and caerulein, the difference observed resulted from a difference in the severity of the damage. However, this is unlikely because the memory deficit induced by the PP lesion per se was greater in the caeruleintreated group (experiment 2) compared with the L-365,260-treated group (experiment 1). The slight improvement observed in the latter group could have originated from compensatory mechanisms operating at the level of the area postrema (see above) or, because CCK-B receptors are widely distributed, to a direct action on these receptors elsewhere in the brain. Experiments using intracerebral injections might give additional information on the precise structures involved, but these studies are limited by the poor solubility of the currently available CCK-B receptor antagonists.

In conclusion, we have shown that the olfactory recognition test is a hippocampal-dependent memory model suitable for pharmacological studies on the neurobiology of memory. Moreover, we confirmed earlier studies showing memory-enhancing potentialities of CCK-A receptor agonists and CCK-B receptor antagonists, and further demonstrated that these effects are transmitted by distinct neuronal pathways. Memory enhancement

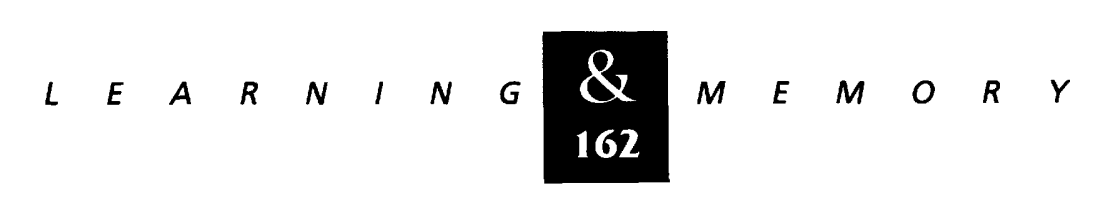


induced by CCK-A receptor agonists appears to involve first a vagal relay from the periphery to the brain; memory enhancement induced by CCK-B receptor antagonists is directly central and involves, at least in part, the hippocampal system.

\section{Acknowledgments}

We thank Jean-Paul Martin for the synthesis of L-365,260 and Karen Pepper for stylistic revision of the manuscript.

The publication costs of this article were defrayed in part by payment of page charges. This article must therefore be hereby marked "advertisement" in accordance with 18 USC section 1734 solely to indicate this fact.

\section{References}

Bertrand, P., G.A. Böhme, C. Durieux, C. Guyon, M. Capet, B. Jeanteaud, P. Boudeau, B. Ducros, C.E. Pendley, G.E. Martin, A. Floch, and A. Doble. 1994. Pharmacological properties of ureido-acetamides, new potent and selective non-peptide $\mathrm{CCK}_{\mathrm{B}}$ /gastrin receptor antagonists. Eur. I. Pharmacol. 262: 233-245.

Böhme, G.A., C. Durieux, J.M. Stutzmann, B. Charpentier, B.P. Roques, and J.C. Blanchard. 1989. Electrophysiological studies with new CCK analogs: Correlation with binding affinity on B-type receptors. Peptides 10: 407-414.

Böhme, G.A., C. Bon, M. Lemaire, M. Reibaud, O. Piot, J.M. Stutzmann, A. Doble, and J.C. Blanchard. 1993. Altered synaptic plasticity and memory formation in nitric oxide synthase inhibitor-treated rats. Proc. Natl. Acad. Sci. 90: 9191-9194.

Branchereau, P., G.A. Böhme, J. Champagnat, M.P. Morin-Surun, C. Durieux, J.C. Blanchard, B.P. Roques, and M. Denavit-Saubié. 1992. Cholecystokinin ${ }_{A}$ and cholecystokinin $_{B}$ receptors in neurons of the brainstem solitary complex of the rat: Pharmacological identification. /. Pharmacol. Exp. Ther. 260: 1433-1440.

Carr, W.J., L. Yee, D. Gable, and E. Marasco. 1976. Olfactory recognition of conspecifics by domestic Norway rats. J. Comp. Physiol. Psychol. 90: 821-828.

Crawley, J.N., S.E. Hays, and S.M. Paul. 1981. Vagotomy abolishes the inhibitory effects of cholecystokinin on rat exploratory behaviors. Eur. J. Pharmacol. 73: 379-380.

Cummings, B.J., G.J. Yee, and C.W. Cotman. 1992. bFGF promotes the survival of entorhinal layer II neurons after PP axotom. Brain Res. 591: 271-276.

Dantzer, R., R.M. Bluthé, G.F. Koob, and M. Le Moal. 1987. Modulation of social memory in male rats by neurohypophyseal peptides. Psychopharmacology 91: 363-368.

Daugé, V., G.A. Böhme, J.N. Crawley, C. Durieux, J.M. Stutzmann, J. Féger, J.C. Blanchard, and B.P. Roques. 1990.
Investigation of behavioral and electrophysiological responses induced by selective stimulation of $\mathrm{CCK}_{\mathrm{B}}$ receptors by using a new highly potent CCK analog, BC 264. Synapse 6: 73-80.

Eichenbaum, H., T. Otto, and N.J. Cohen. 1992. The hippocampus: What does it do? Behav. Neural Biol, 57: $2-36$.

File, S.E. 1985. Animal models for predicting clinical efficacy of anxiolytic drugs: Social behaviour. Neuropsychobiology 13: $55-62$.

Flood, J.F. and J.E. Morley. 1989. Cholecystokinin receptors mediate enhanced memory retention produced by feeding and gastrointestinal peptides. Peptides 10: 809-813.

Flood, J.F., J.S. Garland, and J.E. Morley. 1992. Evidence that cholecystokinin-enhanced retention is mediated by changes in opioid activity in the amygdala. Brain Res. 585: 94-104.

Gaykema, R.P.A., P.G.M. Luiten, C. Nyakas, and J. Traber. 1990. Cortical projection patterns of the medial septum-diagonal band complex. I. Comp. Neurol. 293: 103-124.

Greenwood, R.S., S.E. Godar, T. Albert Reaves Jr., and J.N. Hayward. 1981. Cholecystokinin in hippocampal pathways. J. Comp. Neurol. 203: 335-350.

Hill, D.R. and G.N. Woodruff. 1990. Differentiation of central cholecystokinin receptor binding sites using the non-peptide antagonists MK-329 and L-365,260. Brain Res. 526: 276-283.

Hlinak, Z. and I. Krejci. 1992. Prolonged social recognition in male rats treated with alaptide or oxiracetam. Behav. Pharmacol. 3: 129-131.

Itoh, S. and G. Katsuura. 1986. Behavioral effect of cholecystokinin octapeptide in vagotomized rats. Can. J. Physiol. Pharmacol. 64: 745-747.

Itoh, S. and H. Lal. 1990. Influences of cholecystokinin and analogues on memory processes.Drug Dev. Res.

21: $257-276$.

Jean, A. 1991. Le noyau du faisceau solitaire: Aspects neuroanatomiques, neurochimiques et fonctionnels. Arch. Int. Physiol. Biochim. Biophys. 99: A3-A52.

Jones, R.S.G. 1993. Entorhinal-hippocampal connections: A speculative view of their function. Trends Neurosci. 16: $58-64$.

Johnson, A.K. and P.M. Gross. 1993. Sensory circumventricular organs and brain homeostatic pathways. FASEB I. 7: 678-686.

Kan, J.P., R. Steinberg, F. Oury-Donat, J.C. Michaud, O. Thurneyssen, J.P. Terranova, C. Gueudet, J. Souilhac, R. Brodin, R. Boigegrain, C.G. Wermuth, P. Worms, P. Soubrié, and G. Le Fur. 1993. SR 46559A: A novel and

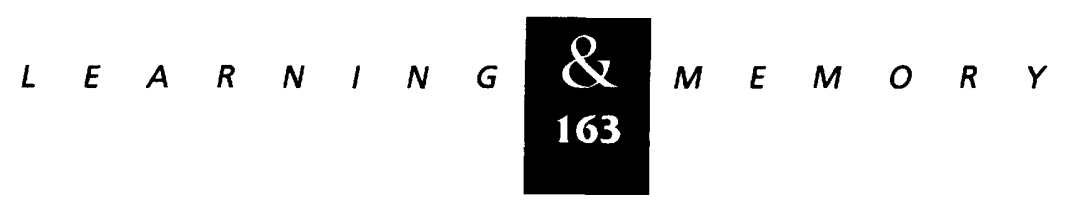




\section{Lemaire et al.}

potent muscarinic compound with no cholinergic syndrome. Psychopharmacology 112: 219-227.

Köhler, C., H. Hallman, and A.C. Radesäter. 1987. Distribution of $\left[{ }^{3} \mathrm{H}\right]$ cholecystokinin octapeptide binding sites in the hippocampal region of the rat brain as shown by in vitro receptor autoradiography. Neuroscience 721: 857-867.

Lee, Y.M., M. Beinborn, E.W. McBride, M. Lu, L.F. Kolakowski Jr., and A.S. Kopin. 1993. The human brain cholecystokinin-B/gastrin receptor. Cloning and characterization. J. Biol. Chem. 268: 8164-8169.

Lemaire, M., O. Piot, B.P. Roques, G.A. Böhme, and J.C. Blanchard. 1992. Evidence for an endogenous cholecystokininergic balance in social memory. NeuroReport 3: 929-932.

Lemaire, M., G.A. Böhme, O. Piot, B.P. Roques, and J.C. Blanchard. 1994. CCK-A and CCK-B selective receptor agonists and antagonists modulate olfactory recognition in male rats. Psychopharmacology 115: 435-440.

Mercer, J.C. and C.B. Lawrence. 1992. Selectivity of cholecystokinin (CCK) receptor antagonists, MK-329 and L-365,260, for axonally-transported CCK binding sites on the rat vagus nerve. Neurosci. Lett. 137: 229-231.

Moran, T.H., P.H. Robinson, M.S. Goldrich, and P.R. McHugh. 1986. Two brain cholecystokinin receptors: Implications for behavioral actions. Brain Res. 362: 175-179.

Myhrer, T. 1988. The role of medial and lateral hippocampal $\mathrm{PP}$ lesions and object distinctiveness in rats' reaction to novelty. Physiol. Behav. 42: 371-377.

Paxinos, G. and C. Watson. 1986. The rat brain in stereotaxic coordinates. Academic Press, San Diego, CA.

Perio, A., J.P. Terranova, P. Worms, R.M. Bluthé, R. Dantzer, and K. Biziére. 1989. Specific modulation of social memory in rats by cholinomimetic and nootropic drugs, by benzodiazepine inverse agonists, but not by psychostimulants. Psychopharmacology 97: 262-268.

Popik, P. and J.M. Van Ree. 1991. Oxytocin but not vasopressin facilitates social recognition following injection into the medial preoptic area of the brain. Eur. Neuropsychopharmacol. 1: 555-560.

Popik, P., P.E. Vos, and J.M. Van Ree. 1992. Neurohypophyseal hormone receptors in the septum are implicated in social recognition in the rat. Behav. Pharmacol. 3: $351-358$.

Sawyer, T.F., A.K. Hengehold, and W.A. Perez. 1984. Chemosensory and hormonal mediation of social memory in male rats. Behav. Neurosci. 98: 908-913.

Scalia, F. and S.S. Winans. 1975. The differential projections of the olfactory bulb and accessory olfactory bulb in mammals. J. Comp. Neurol. 161: 31-56.
Shiosaki, K., C. Wel Lin, H. Kopecka, M.D. Tufano, B.R. Bianchi, T.R. Miller, D.G. Witte, and A.M. Nadzan. 1991. Boc-CCK-4 derivatives containing side-chain ureas as potent and selective CCK-A receptor agonists. J. Med. Chem. 34: 2837-2842.

Skelton, R.W. and R.K. MCNamara. 1992. Bilateral knife cuts to the PP disrupt spatial learning in the Morris water maze. Hippocampus 2: 73-80.

Smith, G.P., C. Jerome, B.J. Cushin, R. Eterno, and K.J. Simanski. 1981. Abdominal vagotomy blocks the satiety effect of cholecystokinin in the rat. Science 213: 1036-1037.

Squire, L.R. 1992. Memory and the hippocampus: A synthesis from findings with rats, monkeys, and humans. Physiol. Rev. 99: 195-231.

Suzuki, W.A. and D.G. Amaral. 1994. Topographic organization of the reciprocal connections between the monkey entorhinal cortex and the perirhinal and parahippocampal cortices. J. Neurosci. 14: 1856-1877.

Swanson, L.W. 1983. The hippocampus and the concept of limbic system. In Neurobiology of the hippocampus (ed. W. Seifert), pp. 3-19. Academic Press, London, UK.

Terranova, J.P., A. Pério, P. Worms, G. Le Fur, and P. Soubrié. 1994. Social olfactory recognition in rodents: deterioration with age, cerebral ischemia and septal lesion. Behav. Pharmacol. 5: 90-98.

Thor, D.H. and W.R. Holloway. 1982. Social memory of the male laboratory rat. J. Comp. Physiol. Psychol.

96: 1000-1006.

Vasar, E., A. Lang, J. Harro, S. Kôks, V. Volke, S. Sihver, M. Bourin, J. Bradwejn, and P.T. Männistö. 1994.

Subdiaphragmatic vagotomy does not prevent the anti-exploratory effect of caerulein in the elevated plus-maze. Neuropeptides 26: 39-45.

Received July 5, 1994; accepted in revised form September 18, 1994.

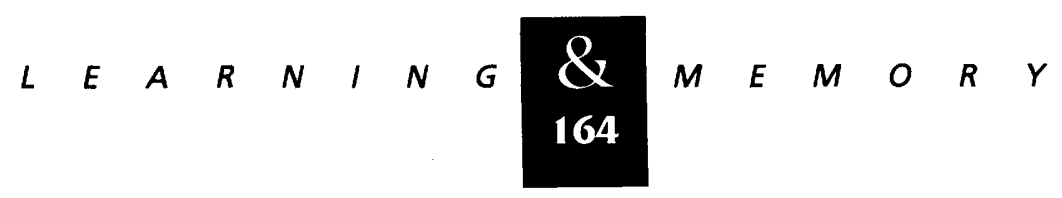




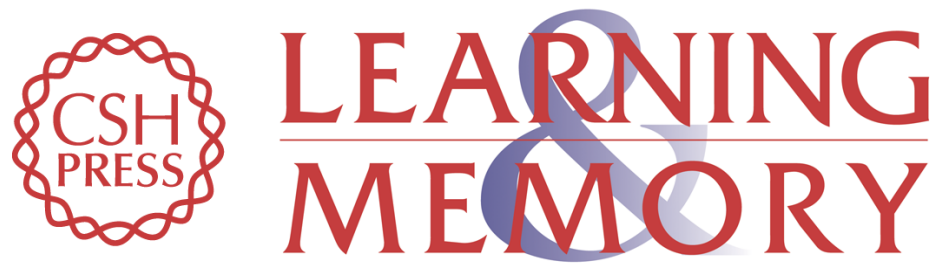

\section{CCK-A and CCK-B receptors enhance olfactory recognition via distinct neuronal pathways.}

M Lemaire, P Barnéoud, G A Böhme, et al.

Learn. Mem. 1994, 1:

Access the most recent version at doi:10.1101//m.1.3.153

References This article cites 43 articles, 5 of which can be accessed free at: http://learnmem.cshlp.org/content/1/3/153.full.html\#ref-list-1

License

Email Alerting Receive free email alerts when new articles cite this article - sign up in the box at the Service top right corner of the article or click here. 